\title{
Can racial identity be promotive of academic efficacy?
}

\author{
Daphna Oyserman \\ University of Michigan, Ann Arbor, \\ USA
}

\author{
Kathy Harrison \\ Wayne State University, Detroit, \\ USA
}

\author{
Deborah Bybee \\ Michigan State University, East Lansing, \\ USA
}

\begin{abstract}
We hypothesised a gender specific relationship between efficacy and three components of racial identity, feeling that achievement is part of being black, feeling connected to the black community, and sensitivity to, awareness of outgroup barriers and racism. Because male gender socialisation downplays relationality, the "connectedness" component of racial identity was posited to be particularly helpful for boys. Because female gender socialisation downplays independent achievement and agency, the "achievement" component of racial identity was posited to be particularly helpful for girls in buffering the negative effects of the "awareness of racism" component. Controlling for fall grades and academic efficacy, fall racial identity significantly predicted spring academic efficacy differentially for boys and girls $(n=91$ African-American eighth graders), with the lack of the achievement component of racial identity being particularly detrimental to girls.
\end{abstract}

Perceived efficacy is central to many accounts of positive youth outcomes as the motivational force bolstering persistence, effort, and other active coping strategies (Petersen, Leffert, Graham, Alwin, \& Ding, 1997; Scheier \& Botwin, 1998). A number of authors have linked feelings of academic efficacy to both better school performance and reduced risk of feeling depressed and anxious (Eccles, Lord, Roeser, Barber, \& Jozefowicz, 1997; Harter, Whitesell, \& Kowalski, 1992). More generally, the subjective experience of competence is central to many theories of adolescent resilience and achievement (Gordon \& Song, 1994; Masten, 1994; Wang, Haertel, \& Walberg, 1994). Yet youth's sense of academic efficacy is likely to decline in the transition to high school (Eccles et al., 1997), as are grades and self-esteem (Petersen et al., 1997). Declines in efficacy are especially sharp in the middle school years (Seidman, Allen, Aber, Mitchell, \& Feinman, 1994; Seidman \& French, 1997; Seidman et al., 1998). It may be that AfricanAmerican males are particularly likely to experience such declining efficacy (Halperin, 1998), though girls are generally more at risk of declining sense of competence in the adolescent years (Crain, 1996; Feingold, 1994).

Declines in performance after elementary school are especially sharp for African-Americans and other minorities (Miller, 1995). African-American underperformance cannot be attributed to lack of interest in school-African-American youth and their parents have high academic and occupational aspirations, higher than whites once socioeconomic status has been controlled for (Graham, 1994; Grant \& Sleeter, 1988; Higginbotham \& Weber, 1992). Another possibility is that African-American inner-city youth may come to view school success as not black and in this way come to disparage their own academic efficacy (Ogbu, 1991). Yet the interplay between academic efficacy and racial-ethnic identity has yet to be explored in detail. Such an exploration is particularly important because a common stereotype about AfricanAmerican focuses on lack of academic ability. This stereotype may have negative consequences for adolescents who struggle to negotiate African-American culture, their status as minorities, and their "fit" with mainstream society (Boykin \& Toms, 1985).

Some qualitative accounts suggest that one result can be an attempt to be "raceless", to de-emphasize race as a way to manage these conflicts and do well in school (Fordham, 1988; Fordham \& Ogbu, 1986). The idea that de-emphasizing race (and gender and social class) can reduce the deflating effects of negative in- and outgroup stereotypes on performance has been examined in a series of studies focused on the performance of college students (Croizet \& Claire, 1998; Steele, 1997). Race, social class, and gender were each shown to be disruptive of performance when made salient and when negative stereotypes about the group's academic performance exist. Similarly, when a positive stereotype exists- such as the "model minority" stereotype of Asian academic ability (e.g., Oyserman \& Sakamoto, 1997), then making the identity (e.g., being Asian-American) salient is promotive of performance (Shih, Pittinsky, \& Ambady, 1999). Thus, from experimental research with college students, it seems that making one's racial identity salient may be promotive or deflating of competence depending on whether the content of one's racial identity is positive with regard to academics or leaves one vulnerable to negative stereotypes about one's group. Yet content of racial identity has not been directly assessed in this research.

\section{Linking racial identity and academic efficacy}

A wide array of authors has suggested that it is important to have a positive racial identity (Allen, Dawson, \& Brown, 1989; Azibo, 1991; Hudson, 1991; Jackson, 1992; Jackson, McCullough, Gurin, \& Broman, 1991; Jencks, 1991; Kirschenman \& Neckerman, 1991; McAdoo, 1991; McNair-Knox, 1991; Whittler, Calantone, \& Young, 1991). Although correlated 
with higher self-esteem, less stress and less delinquent involvement in adolescence (Phinney \& Kohatsu, 1997; McCreary, Slavin, \& Berry, 1996; Spencer, Cunningham, \& Swanson, 1995), the connection of racial identity to academic efficacy is less clear. However, by thinking more carefully about what content of racial identity would be relevant to academic efficacy and taking a developmental focus, it may be possible to address this gap.

We focus on three aspects of racial identity that, as we shall outline in the following sections, are relevant to the relationship between content of racial identity and academic efficacy. These are: positive ingroup identification, awareness of negative outgroup perceptions, and viewing academic achievement as part of one's racial identity. Positive ingroup identification or "connectedness" can entail having a positive sense of connection to black people, a sense of connection, common fate, and solidarity with other blacks. Although alone it is not necessarily related to academic efficacy, as we shall outline later, it may balance out the autonomy focus of male gender socialisation and focus needed attention on complying with group norms and values. The second racial identity component, "awareness of racism" entails being aware that others are likely to define one's self negatively and see the self only as a member of a negatively valued group. This component of racial identity may protect self-esteem by providing a nonself-denigrating framework for understanding others' negative responses but can also dampen perceived academic efficacy by making salient that one may fail due to no fault of one's own (Crocker \& Major, 1989). As will be outlined later, this component of racial identity is proposed to influence boys and girls differently. In particular, awareness of racism is likely to have a more dampening effect on girls and a more liberating effect on boys. For girls, relationality and the positive opinions of others are likely to be more centrally self-defining, whereas for boys, as autonomy is more valued, awareness of racism allows failure to be depersonalised as due to racism and therefore not provide negative self-evaluative feedback.

The third component of racial identity relevant to our analyses, "embedded achievement" focuses on the extent that academic achievement is viewed as integral to or embedded into one's racial-ethnic group (Oyserman, Gant, \& Ager, 1995; Oyserman \& Sakamoto, 1997). By defining academic achievement as an ingroup-defining trait or value, this component of racial identity serves to reduce possible tensions between achievement and minority racial group membership. Although not necessarily universally present in racial identity, when present, this component can serve to focus attention and motivation on ways to learn, do well and succeed, bolstering academic efficacy by making achievement a function of ingroup membership. As will be described later, this component of racial identity is likely to be particularly beneficial to girls, because it complements or balances out the more typical relationality focus of girls' self-concepts (for reviews of the ways self-concept differs for boys and girls see Cross \& Madson, 1997; Markus \& Oyserman, 1989).

\section{$A$ developmental approach to racial identity}

In the current study we explore the interplay between content of racial identity and gender for young adolescents approaching the beginning of high school in impoverished inner-city areas. We take a developmental approach, integrating what is known about shifts in content of self-concept across school-aged and adolescent years into our conceptualisation of racial identity. A developmental approach to racial identity highlights the shifting focus of self-concept content as well as its increased complexity during the sociocognitive developmental transitions of adolescence. For example, during the school-aged years, content of self-concept shifts from focus on physical attributes to the self's skills and abilities (Harter, 1999). With adolescence, content of the self-concept shifts again to take in both social roles and aspirations and desires of the self (Damon \& Hart, 1988). Therefore, with regard to racial identity, it seems plausible that content of racial identity also shifts from physical markers of membership, to focus on the skills and competencies of one's racial group during the school-aged years (Quintana, 1998). Social roles include gender and race as well as social class. With early adolescence, girls and boys diverge in their self-esteem, sense of efficacy, agency, and the extent they feel defined by their relationships to others and connections with them. A large body of research suggests that girls and young women are more relational in their self-concept than boys and young men are (for a review, see Cross \& Madson, 1997).

In addition to a focus on the group's skills and abilities, with adolescence, there may emerge a more abstract sense of membership in a particular racial-ethnic group, to the exclusion of other groups, and an intertwining of group membership and future possibilities as part of racial identity. It may be that the relationship between racial identity and perceived academic efficacy is particularly important in the school-aged years as children and adolescents focus on skills, competencies, and social identities in their self-concepts (Oyserman, in press). Racial identity may be a particularly central aspect of identity in adolescence, as youth seek membership in nonfamily groups as part of their separation and individuation from their families. Further, racial identity can balance out gender-specific differences in self-conceptthe focus on independence and agentic action for boys and social connection and relationality for girls, by making connection to the ingroup community and achievement as part of membership in this group self-defining for boys and girls, respectively.

Thus, the relational component of racial identity was posited to connect boys to communal institutions and values, instilling a sense of competence as part of group membership. For girls, gender socialisation already is likely to make relationality central to self-concept (Bakan, 1966). For them, the striving and achievement-oriented component of racial identity was posited to serve to make achievement relevant to and part of a relational sense of self, rather than competing with this gender-relevant self-definition. For both boys and girls, awareness of racism was assumed to be potentially risky in that it would be likely to prompt disengagement from domains in which one's group was negatively defined by the outgroup unless buffered by the gender-appropriate additional component-connectedness and embedded achievement. In this way, we postulated that gender-specific racial identity can be promotive of a connected yet achievement-focused sense of self that is likely to buffer academic efficacy.

The current study, focused on the last year of middle school, provides an initial step in studying the interplay between gender-specific racial identity and feelings of academic efficacy. The last year of middle school, eighth grade, is considered a critical period. Students who transfer to high 
school and lack the belief that they can master increasingly difficult coursework are less likely to plan to attend college and less likely to complete high school (Halperin, 1998).

\section{Study}

Controlling for average grades attained, we examined the extent that components of racial identity and academic efficacy were positively correlated in the fall of the eighth grade and then, controlling grades and fall academic efficacy, we examined the relationship between racial identity and academic efficacy in the spring. This is a strong test of the relationship because the controls reduce substantially the potential confounding influence of unmeasured variables by controlling for them in the fall measures.

\section{Participants}

Participants were African-American male and female eighth grade students from a high poverty inner-city Detroit middle school (92\% receiving free and/or reduced cost lunch). According to Census track information, the school was situated in an area with higher than Detroit average number of family households at or below the poverty line (49\% vs. $29 \%$ ).

\section{Procedure}

Parents were mailed letters explaining the purpose of the study and its anonymous and voluntary nature. They were provided self-addressed postage-paid response postcards and then contacted by phone if cards were not returned to ensure full participation. The study was part of a larger school effort to improve academic performance, therefore an array of questions were asked only some of which are relevant for the current study. Students involved in a school-based intervention to promote performance were not included in this analysis. Participants were administered the study materials in a classroom setting. The second author and an additional African-American graduate student assistant remained in the classroom to answer questions during the study session. Study materials were administered in the first month and again in the final weeks of the academic year. Data from two consecutive cohorts of eighth graders were combined after initial tests verified that they were not significantly different on any of the variables assessed in this study. All data represent this combined sample.

As an inner-city, high poverty school, the middle school experienced large shifts in its student body over the course of the school year. Therefore, data are analysed both for all the 126 youth (61 male, 65 female) who filled out the fall questionnaire and for the 91 youth ( 44 male and 47 female) who filled out the questionnaire in both fall and spring. Youth who completed both the fall and the spring questionnaires had higher academic efficacy scores compared with the 35 who completed only the fall measure, $t(124)=2.02, p<.05 ; M$ fall only $=3.85 ; M$ both $=4.12$, and compared with the 37 who completed only the spring measure, $t(126)=1.92 ; p<.06 ; M$ spring only $=3.73 ; M$ both $=3.99$, suggesting that perhaps school stability is promotive of efficacy. Those who completed both the fall and spring measures were not significantly different from the fall-only or spring-only groups on grades or racial identity.

\section{Measures}

Academic efficacy. This was assessed in the fall and spring with the Eccles (1993) School Efficacy Scale, a 6-item 5-point Likert response scale $(1=$ not at all, $2=$ a little, $3=$ somewhat, $4=$ mostly, $5=$ very well). Students responded to items such as: "How well can you get teachers to help you when you get stuck on schoolwork?" "How well can you finish homework assignments by deadlines?" "How well can you live up to the expectations of teachers?" "How well can you remember information presented in class and textbooks?" Eccles reports alphas between .78 and .81 , and reliability for the current sample was comparable, Cronbach's alpha $=.76$ fall and .79 spring (fall $M=4.07, \mathrm{SD}=0.67$; spring $M=3.91, \mathrm{SD}=$ $0.72)$.

Racial-ethnic identity. This was measured in the fall with three 3-item 5-point Likert response scale subscales ( $1=$ strongly disagree, 2 = disagree, $3=$ neither agree nor disagree, $4=$ agree, 5 = strongly agree), based on Oyserman et al. (1995). Sample items are "I feel part of the black community" (connectedness), "Because I am black, others may have negative expectations of me" (awareness of racism), and "I have a lot of pride in what members of my community have done and achieved" (embedded achievement). Subscale reliability was in the low-adequate range, connectedness $(M$ $=4.13, \mathrm{SD}=0.79)$ alpha $=.74$, awareness of $\operatorname{racism}(M=$ $3.46, \mathrm{SD}=0.88)$, alpha $=.62$, and embedded achievement $(M=3.69, \mathrm{SD}=0.86)$, alpha $=.65$. Similar levels of reliability are reported for other racial identity scales (8-item measure, alpha $=.69$, Paschall \& Hubbard, 1998; reliability in the .5 to .6 range, Sellars, Rowley, Chavous, Shelton, \& Smith, 1997). It may be that scales attempt to measure content that is too heterogeneous or that respondents have conflicting perceptions about their identity (Shelton, 1999).

Self-reported grades. These were obtained as a control for the influence of academic performance on academic efficacy. A single item 9 -point scale was used ( $0=$ mostly Fs, $1=$ mostly Ds and Fs, $2=$ mostly Ds, $3=$ mostly Cs and Ds, $4=$ mostly Cs, $5=$ mostly Cs and Bs, $6=$ mostly Bs, $7=$ mostly As and Bs, and $8=$ mostly As). ${ }^{1}$

\section{Results}

To study the gender-specific effects of racial identity on academic efficacy we used hierarchical, moderated regression. This strategy allowed us to examine the interaction of gender and racial identity, after controlling for the main effects of gender and racial identity as well as lower order interactions among the racial identity components. First, we assessed the concurrent relationship between academic efficacy and genderspecific racial identity and then we assessed the relationship between fall racial identity and spring academic efficacy. This latter analysis used panel data, which allowed us to control for

${ }^{1}$ School records of grades were obtained for those youth with grades on file but were not always available. Self-report of grades correlated significantly with available records. Grades averaged about a B whether grades were from school records $(M=2.94$ on a 4 -point scale) or from self-reports $(M=6.10$ and 6.14 in the fall and spring, respectively), and self-reported grades strongly correlated with school record of grades, $r=.74 p<.001$ ). 
prior (fall) grades and level of academic efficacy and to use fall levels of racial identity to predict spring levels of academic efficacy. As delineated by Finkel (1995), this model of analysis has several important strengths. First, because the regression model contains a measure of prior level of grades and academic efficacy, regression coefficients can be interpreted as predictive of change in academic efficacy over the academic year. Second, because the model takes into account prior level of grades and academic efficacy, unmodelled influences on school involvement are at least partially controlled, allowing a clear focus on the modelled predictors - the interactions of gender and racial identity. Finally, because the predictors are lagged (measured at a prior point in time), the analysis allows for strong conclusions about the direction of influence between genderspecific racial identity and academic efficacy.

Analysis utilised a hierarchical regression equation in which spring level of academic efficacy was predicted by the interaction between gender and the components of racial identity, entered in the final blocks of the model (blocks 6-8). In the preceding steps we entered, as controls, prior grades and academic efficacy, gender, and racial identity variables. At block 1 we entered fall grades; at block 2 we entered fall academic efficacy; at block 3, gender; at block 4, main effects for each of the three components of racial identity; at block 5, two-way interactions between the three components of racial identity; and at block 6 , the three-way interactions among the racial identity components. Blocks 6 through 8 incorporated gender in interaction with each racial identity main effect and interaction: block 6 contained two-way interactions between gender and each component of racial identity; block 7 contained three-way interactions, and block 8 added the four-way interaction between gender and all three racial identity components.

Our analyses follow the recommendations of Aiken and
West (1991) for structuring, probing, and interpreting higherorder interactions in a multiple regression framework. As they suggest, we used plots and tests of the significance of simple slopes to illuminate the nature of the higher order interactions. For the significant interaction, a plot illustrates the simple slope of one interacting variable estimated at all possible combinations of high $(M+1 \mathrm{SD})$ and low $(M-1 \mathrm{SD})$ levels of the other variables involved in the interaction (Figures 1 and 2). Despite our modest sample size, power was adequate to detect the hypothesised four-way interaction given the control for prior (fall) levels of the dependable variable. With the stability of academic efficacy from fall to spring exceeding .50, power to detect a moderating relationship accounting for $5 \%$ of the variance in change was approximately .70 .

\section{Does racial identity relate to academic efficacy?}

Fall analyses. We hypothesised that racial identity promotes academic efficacy differently for boys and girls. We first examined this relationship cross-sectionally, with all data collected in the fall. As predicted, racial identity added significantly to the prediction of academic efficacy. Specifically, in addition to the relationship between school grades and academic efficacy at block $1, F(1,124)=8.74, p<.01, R^{2}=$ .07 , racial identity, and specifically the achievement component of racial identity, improved model fit significantly at block $3, \Delta F(3,120)=4.10, p<.01 ; \Delta R^{2}=.09$, achievement $\beta=$ $.21, p<.01$. This effect was moderated by the interaction between racial identity and gender, specifically the interaction between the awareness of racism component of racial identity and gender at block 6 which significantly improved model fit, $\Delta F(3,113)=4.24, p<.01 ; \Delta R^{2}=.08, R^{2}=.27$, adjusted $R^{2}$ $=.19$, gender $\times$ racism $\beta=.43, p<.001$. Thus, viewing achievement as part of being African-American bolstered

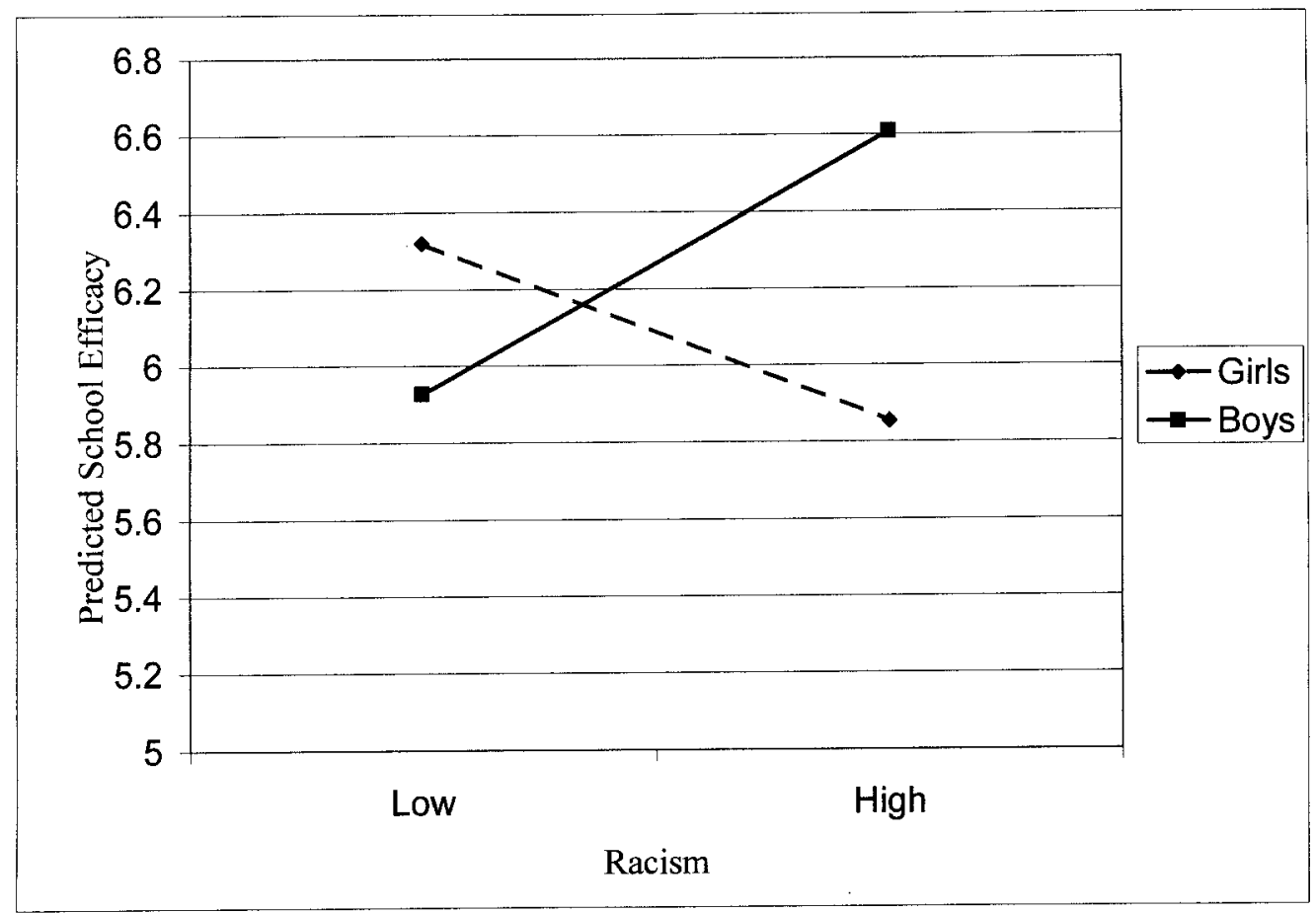

Figure 1. Relationship between racial identity and school efficacy in the fall, controlling for grades. 
academic efficacy for both boys and girls. In addition, as can be seen in Figure 1, for boys, awareness of racism also appeared to bolster feelings of academic efficacy, whereas for girls, awareness of racism had a negative influence on feelings of academic efficacy. Feeling that one may be labelled as a group member was differentially related to academic efficacy for boys and girls. Because these analyses are cross-sectionally, further interpretation is held for the next set of analyses.
Spring analyses. Following the literature, we expected to find declining levels of academic efficacy over the course of the school year. A trend level decline was found, $t(90)=1.86, p<$ .07 . For boys and girls respectively, mean efficacy in fall was 4.18 and 4.06 and declined to 4.06 and 3.92 in the spring. We predicted that racial identity would function to stave off this decline differently for boys and girls. As predicted, racial identity added significantly to the prediction of academic


Figure 2. Relationship between fall racial identity and spring school efficacy, controlling for grades and fall school efficacy. 
efficacy. Prior levels of academic efficacy and school grades improved model fit at block $1, F(1,89)=36.81, p<.001, R^{2}$ $=.29$, and block $2, \Delta F(1,88)=3.90, p=.05 ; \Delta R^{2}=.03$. Model fit was again significantly improved at block 9 with the inclusion of the four-way racial identity components by gender-interaction effect, $\Delta F(1,73)=6.73, p=.01 ; \Delta R^{2}=$ $.05, R^{2}=.48$, adj. $R^{2}=.36$. As can be seen in Figure 2, controlling for grades and previous sense of efficacy, content of racial identity influenced feelings of efficacy in the spring, and the pattern of effects was different for boys and girls. Recall that we hypothesised that awareness of racism would be deflating if not bolstered by high belief in achievement as part of being black (for girls) and connectedness (for boys). We find some support for these hypothesised relationships. For girls, the biggest decline in academic efficacy occurs among girls who are high in awareness of racism and connectedness but low in the achievement-focused component of racial identity. For girls, then, feeling connected to and part of a group that one feels is negatively viewed by others is detrimental to academic efficacy only when one does not view achievement as part of one's ingroup identity. For boys, controlling for school grades and fall levels of efficacy, no significant effect is found-the positive effects of the achievement and awareness of racism components seen cross-sectionally are no longer evident in the longitudinal analyses.

\section{Discussion}

We chose to focus on how racial identity may provide a positive buffer against declining academic efficacy because efficacy is a motivational force and it is clear that being a member of a minority group can be deflating and stigmatising. Because race is clearly a socially constructed category with important social consequences (Schaefer, 1991), understanding how youth incorporate racism into their identity clearly warrants further study. In a race-conscious society, such as that in the United States, it is likely that race may be an almost ubiquitous social fact about the self, used by others to make sense of one's abilities and aspirations. Therefore, it is likely that racial identity is commonly used to make sense of one's self, especially in adolescence (e.g., Quintana, 1998). Yet simply knowing one's race is not enough in adolescence. With their ability to think abstractly, teenagers are likely to view race as a marker for belongingness and ingroup and outgroup others' expectations for people like one's self. For example, among college students, making ethnicity-race salient has been related to increased salience of negative stereotypes about one's group and performance decrements (Steele, 1997).

In thinking about the ways racial identity can impact academic efficacy we proposed that racial identity is likely to work differently for boys and girls. We posited that the achievement component of racial identity would be particularly central for girls and would buffer girls from loss of efficacy even when awareness of racism was high. Conversely, we proposed that the connectedness component of racial identity would be particularly helpful for boys. We argued that racial identity would be particularly helpful for boys. We argued that racial identity provides a means to take on as self-defining the nongender-emphasised elements of racial identity-positive sense of connection for boys, and achievement as self-defining for girls. In fact, a positive function for the achievement component of identity was found for girls in both the cross- sectional and longitudinal analysis. For boys, effects were weaker and significant only in the within-time analyses. Although preliminary, our results suggest that thinking of racial identity as gender-specific and as potentially complementing other gender-specific self-views, holds promise.

One clear limitation of the current research has to do with the measurement of racial identity. Children as young as four have a more positive attitude toward their own racial-ethnic group than toward others (Bennett, Lyons, Sanio, \& Barrett, 1998) so that it is clear that some form of racial-ethnic identity is an early candidate for self-concept. However, as in many of the domains of self-concept, scaling is problematic. Individuals are socialised in contexts that made salient certain elements of their phenotypes (e.g., skin colour) and set up circumstances in which sharing these phenotypic elements create a sense of commonalities of response and sense of common fate (Phinney \& Kohatsu, 1997). In such circumstances, making sense of what it means to be a member of one's racial group and resolving tensions between racial group membership, negative stereotypes and positive attainments are critical. Yet, developing a scale to assess these issues, especially given sensitivities due to concerns about stereotyping, is difficult.

In the face of stereotypical images of racial and ethnic minorities, sense of cultural difference and restricted opportunities, adolescents of colour must create a sense of self that includes a positive sense of shared social identity with others of their own group. Our project focused on academic efficacy because youth are more likely to invest effort in those endeavours they believe they are competent in and can succeed in (Eccles \& Wigfield, 1995; Eccles, Wigfield, Harold, \& Blumenfeld, 1993). Although efficacy and self-esteem gradually increase in late adolescence (Petersen et al., 1997), for many youth, efficacy and particularly school-related efficacy declines in the transition years bridging middle and high school, and youth with the greatest declines are those most at risk of academic failure (Eccles et al., 1997). In our sample, we found some evidence for declining sense of efficacy over the course of the last year of middle school, and found that genderspecific content of African-American racial identity moderated this effect. Gender differences have been found in efficacy in other research, although not necessarily with African-American samples (e.g., Marsh, 1989). Although clearly only a first step, our research highlights the importance of examining the interface between race and sex in making sense of the content and implications of racial identity in adolescence.

Manuscript received December 1998 Revised manuscript received April 2000

\section{References}

Aiken, L.S., \& West, S.G. (1991). Multiple regression: Testing and interpreting interactions. Newbury Park, CA: Sage.

Allen, R., Dawson, M., \& Brown. R. (1989). A schema-based approach to modeling an African-American racial belief system. American Political Science Review, 83, 421-441.

Azibo, D.A.Y. (1991). An empirical test of the fundamental postulates of an African personality metatheory. The Western fournal of Black Studies, 15, 183195.

Bakan, D. (1966). The duality of human existence. Chicago, IL: Rand McNally.

Bennett, M., Lyons, E., Sanio F., \& Barrett, M. (1998). Children's subjective identification with the group and in-group favoritism. Developmental Psychology, 34, 902-909.

Boykin, A., \& Toms, F. (1985). Black child socialization: A conceptual framework. In H. McAdoo \& J. McAdoo (Eds.), Black children: Social, educational, and parental environments (pp. 33-51). Thousand Oaks, CA: Sage. 
Crain, R. (1996). The influence of age, race, and gender on child and adolescent multidimensional self-concept. In B.A. Bracken (Ed.), Handbook of selfconcept: Developmental, social, and clinical considerations (pp. 395-420). New York: Wiley.

Crocker, J. \& Major, B. (1989). Social stigma and self-esteem: The selfprotective properties of stigma. Psychological Review, 96, 608-630.

Croizet J., \& Claire T. (1998). Extending the concept of stereotype threat to social class: The intellectual underperformance of students from low socioeconomic backgrounds. Personality and Social Psychology Bulletin, 24, 588594

Cross, S.E., \& Madson, L. (1997). Models of the self: Self-construals and gender. Psychological Bulletin, 122, 5-37.

Damon, W. \& Hart, D. (1988). Self-understanding in childhood and adolescence. New York: Cambridge University Press.

Eccles, J. (1993). Middle School Family Survey Study 1993. Institute of Behavioral Sciences, University of Colorado, USA.

Eccles, J., Lord, S., Roeser, R., Barber, B. \& Jozefowicz, D. (1997). In J. Schulenberg, J. Maggs, \& K. Hurrelmann (Eds.), Health risks and developmental transitions during adolescence (pp. 283-320). New York: Cambridge University Press.

Eccles, J., \& Wigfield, A, (1995). In the mind of the actor: The structure of adolescent achievement task values and expectancy-relate $\mathrm{d}$ beliefs. Personality and Social Psychology Bulletin, 21, 215-225.

Eccles, J., Wigfield, A, Harold, R., \& Blumenfeld, P. (1993). Age and gender differences in children's self and task perceptions in elementary school. Child Development, 64, 830-847.

Feingold, A, (1994). Gender differences in personality: A meta analysis. Psychological Bulletin, 116, 429-456.

Finkel, S.E. (1995). Causal analysis with panel data. Sage University Paper series on Quantitative Applications in the Social Sciences, 07-105. Thousand Oaks, CA: Sage.

Fordham, S. (1988). Racelessness as a strategy in Black students' school success: Pragmatic strategy or pyrrhic victory? Harvard Educational Review, 58, 54-84.

Fordham, S, \& Ogbu, J.U. (1986). Black students school success: Coping with the "burden of acting white". The Urban Review, 18, 176-206.

Gordon, E., \& Song, L. (1994). Variations in the experience of resilience. In M. Wang \& E. Gordon (Eds.), Educational resilience in inner-city America: Challenges and prospects (pp. 27-44). Hillsdale, NJ: Erlbaum.

Graham, S. (1994). Motivation in African Americans. Review of Educational Research, 64, 55-117.

Grant, C.A., \& Sleeter, C.E. (1988). Race, class and gender and abandoned dreams. Teachers College Record, 90, 19-40.

Halperin, S. (1998). Summary. In S. Halperin (Ed.), The forgotten half revisited (pp. I-VIII). Washington, DC: American Youth Policy Forum.

Harter S. (1999). The construction of the self: $A$ developmental perspective. New York: Guilford Press.

Harter, S., Whitesell, N., \& Kowalski, P. (1992). Individual-difference s in the effects of educational transitions on young adolescent's perceptions of competence and motivational orientation. American Educational Research fournal, 29, 777-807.

Higginbotham E., \& Weber, L. (1992). Moving up with kin and community. Gender and Society, 6, 416-440.

Hudson, R. (1991). Black male adolescent development deviating from the past: Challenges for the future. In B. Bowser (Ed.), Black male adolescents: Parenting and education in community context (pp. 271-281). Lanham, MD: University Press of America.

Jackson, F. (1992). Race and ethnicity as biological constructs. Ethnicity and Disease, 2, 120-125.

Jackson, J.S., McCullough, W.R., Gurin, G. \& Broman, C. (1991). Race identity. In J. Jackson (Ed.), Life in Black America: Findings from a national survey. Newbury Park, CA: Sage.

Jencks, C. (1991). Is the American underclass growing? In C. Jencks \& P.E. Peterson (Eds.), The urban underclass. Washington, DC: Brookings Institution.

Kirschenman, J., \& Neckerman, K.M. (1991). "We'd love to hire them, but ...": The meaning of race for employers. In C. Jencks, \& P.E. Peterson (Eds.), The urban underclass (pp. 203-232). Washington, DC: Brookings Institution.

Markus, H., \& Oyserman, D. (1989). Gender and thought: The role of the selfconcept. In M. Crawford \& M. Gentry (Eds.), Gender and thought: Psychological perspectives (pp. 100-127). New York: Springer.

Marsh, H. (1989). Age and sex effects in multiple dimensions of self-concept. Preadolescence to early adulthood. Fournal of Educational Psychology, 81, 417430.

Masten, A. (1994). Resilience in individual development: Successful adaptation despite risk and adversity. In M. Wang \& E. Gordon (Eds.), Educational resilience in inner-city America: Challenges and prospects (pp. 3-26). Hillsdale, NJ: Erlbaum.

McAdoo, J. (1991). The roles of Black fathers in the socialization of Black children. In H. McAdoo (Ed.), Black families (pp. 257-269). Newbury Park, CA: Sage.

McCreary, M., Slavin, L., \& Berry, E. (1996). Predicting problem behavior and self-esteem among African-American adolescents. Fournal of Adolescent Research, 11, 194-215.

McNair-Knox, F. (1991). Tapping into teen talk: Parenting strategies for bridging the intergenerational communication gap. In B. Bowser (Ed.), Black male adolescents: Parenting and education in community context (pp. 235-258). Lanham, MD: University Press of America.

Miller. L.S. (1995). An American imperative. Accelerating minority educational advancement. London/New Haven, CT: Yale University Press.

Ogbu, J. (1991). Minority coping responses and school experience. Fournal of Psychohistory, 18, 433-456.

Oyserman, D. (in press). Self-concept and identity. In A. Tessor \& N. Schwarz (Eds.), Blackwell handbook of social psychology. Oxford, UK: Oxford University Press.

Oyserman, D., Gant, L., \& Ager, J. (1995). A socially contextualize d model of African-American identity: Possible selves and school persistence. Fournal of Personality and Social Psychology, 69, 1216-1232.

Oyserman, D., \& Sakamoto, I. (1997). Being Asian American: Identity, cultural constructs, and stereotype perception. Fournal of Applied Behavioral Science, 33, 433-451.

Paschall, M., \& Hubbard, M. (1998). Effects of neighbourhood and family stressors on African American male adolescents' self-worth and propensity for violent behavior. Fournal of Consulting and Clinical Psychology, 66, 825831.

Petersen, A., Leffert, N., Graham, B., Alwin, J., \& Ding, S. (1997). Promoting mental health during the transition to adulthood. In J. Schulenberg, J. Maggs, \& K. Hurrelmann (Eds.), Health risks and developmental transitions during adolescence, (pp. 471-497). New York: Cambridge University Press.

Phinney, J., \& Kohatsu, E. (1997). Ethnic and racial development and mental health. In J. Schulenberg, J. Maggs, \& K. Hurrelmann (Eds.), Health risks and developmental transitions during adolescence (pp. 420-443). New York: Cambridge University Press.

Quintana, S.M. (1998). Children's developmental understanding of ethnicity and race. Applied and Preventive Psychology, 7, 27-45.

Schaefer, R.T., (1991). Racial and ethnic groups. New York: Harper Collins.

Scheier, L., \& Botwin, G. (1998). Relations of social skills, personal competence and adolescent alcohol use: A developmental exploratory study. Fournal of Early Adolescence, 18, 77-114.

Seidman, E., Allen, L., Aber, J.L., Mitchell, C., \& Feinman, J. (1994). The impact of school transitions in early adolescence on the self-system and social context of poor urban youth. Child Development, 65, 507-522.

Seidman, E., \& French, S.E. (1997). Normative transitions in urban schools during adolescence: The optimal timing and nature of preventive interventions. In H.J. Walberg, O. Reyes, \& R.P. Weissberg (Eds.), Children and youth: Interdisciplinary perspectives (pp. 166-189). Thousand Oaks, CA: Sage.

Seidman, E., Yoshikawa, H., Roberts, A., Chesir-Teran, D., Allen, L., Friedman, J., \& Aber, J. (1998). Structural and experiential neighbourhood contexts, developmental stage and antisocial behavior among urban adolescents in poverty. Development and Psychopathology, 10, 259-281.

Sellers R., Rowley, S., Chavous, T., Shelton, J. \& Smith, M. (1997). Multidimensional inventory of black identity: A preliminary investigation of reliability and construct validity. Fournal of Personality and Social Psychology, $73,805-815$.

Shelton, J. (1999) Let's talk about race. Talk presented at the Group Dynamics Seminar, University of Michigan, Ann Arbor.

Shih, M., Pittinsky, T.L., \& Ambady, N. (1999). Stereotype susceptibility: Identity salience and shifts in quantitative performance. Psychological Science, $10,80-84$

Steele, C. (1997). A burden of suspicion: How stereotypes shape the intellectual identities and performance of women and African-Americans. American Psychologist, 52, 613-629.

Spencer, M., Cunningham, M., \& Swanson, D. (1995). Identity as coping Adolescent African-American males' adaptive responses to high-risk environments. In H. Harris, H. Blue. \& E. Griffith (Eds.), Racial and ethnic identity: Psychological development and creative expression (pp. 31-52). New York: Routledge.

Wang, M., Haertel, G., \& Walberg, H. (1994). Educational resilience in inner cities. In: M. Wang \& E. Gordon (Eds.), Educational resilience in inner-city America: Challenges and prospects (pp. 45-72). Hillsdale, NJ: Erlbaum.

Whittler, T.E., Calantone, R.J., \& Young, M.R. (1991). Strength of ethnic affiliation: Examining Black identification with Black culture. Fournal of Social Psychology, 131, 461-467. 